\title{
PREPARAÇÃO PARA A
}

\section{APOSENTADORIA: INTERVENÇÃO EM UM SERVIÇO PÚBLICO MUNICIPAL}

Marlize Paulo da Silva

Prefeitura Municipal de Maringá

Lucy Leal Melo-Silva

Universidade de São Paulo
Recebido em: 19/07/2019

$1^{\text {a }}$ revisão em: 04/11/2019

Aceito em: 18/11/2019

\section{RESUMO}

O trabalho ocupa um lugar de centralidade na vida humana, de modo que intervenções acerca da transição trabalho-aposentadoria vêm sendo desenvolvidas objetivando facilitar o desenvolvimento profissional ao longo da vida, sobretudo no estágio de desengajamento. Este estudo objetivou descrever e analisar os resultados de um programa de preparação para a aposentadoria (PPA). Em quatro anos do programa participaram 122 pessoas com idade média de 57 anos $(\mathrm{DP}=1,52)$. O programa foi desenvolvido em oito encontros, nos quais foram abordados os seguintes temas: vida financeira, empreendedorismo, saúde e envelhecimento, família, vida social, trajetória socioprofissional e projetos de futuro. Por meio de autoavaliações, comparando a situação pré e pós intervenção, os participantes registraram mudanças relevantes nos sentimentos e recursos internos para enfrentamento da transição trabalho- aposentadoria. Foram apontadas possibilidades de aprimoramento do programa e de implementação de políticas públicas para a aposentadoria e o envelhecimento digno, considerando o cenário econômico e previdenciário brasileiro.

Palavras-chave: trabalho; aposentadoria; desenvolvimento profissional; estágios de desenvolvimento. 


\title{
RETIREMENT PREPARATION: INTERVENTION IN A MUNICIPAL PUBLIC SERVICE
}

\begin{abstract}
Work occupies a central place in human life, so that interventions about the workretirement transition have been developed aiming at facilitating life-long professional development, especially at the disengagement stage. This study aimed to describe and analyze the results of a retirement preparation program (PPA). In four years of the program participated 122 people with average age of 57 years $(S D=1,52)$. The program was developed in eight meetings, in which the following topics like: financial life, entrepreneurship, health and aging, family, social life, socio-professional trajectory and future projects. Through self-assessments comparing the pre and post intervention situation, participants recorded relevant changes in feelings and internal resources to cope with work-retirement transition. Possibilities in order to improve the program and implementation of public policies for retirement and decent aging were pointed out, considering the Brazilian economic and social security scenario.
\end{abstract}

Keywords: labor; retirement; professional development; development stages. 


\section{PREPARACIÓN PARA LA JUBILACIÓN: INTERVENCIÓN EN UN SERVICIO PÚBLICO MUNICIPAL}

\section{RESUMEN}

El trabajo ocupa un lugar central en la vida humana, por lo que las intervenciones sobre la transición trabajo-jubilación se han desarrollado con el objetivo de facilitar el desarrollo profesional de por vida, especialmente en la etapa de desconexión. Este estudio tuvo como objetivo describir y analizar los resultados de un programa de preparación para la jubilación (PPA). En cuatro años del programa participaron 122 personas con una edad promedio de 57 años (DE $=1,52$ ). El programa se desarrolló en ocho reuniones, en las que se abordaron los siguientes temas: vida financiera, emprendimiento, salud y envejecimiento, familia, vida social, trayectoria socioprofesional y proyectos futuros. A través de autoevaluaciones, comparando la situación previa y posterior a la intervención, los participantes registraron cambios relevantes en los sentimientos y los recursos internos para hacer frente a la transición trabajo-jubilación. Se señalaron las posibilidades de mejora del programa y la implementación de políticas públicas para la jubilación y el envejecimiento digno, considerando el escenario económico y de seguridad social brasileño.

Palabras clave: trabajo; jubilación; desarrollo profesional; estados del desarrollo. 


\section{INTRODUÇÃO}

A carreira é um construto teórico e prático largamente difundido por diversos teóricos sendo que, no domínio da Psicologia Vocacional, Donald Super trouxe a compreensão ampliada do termo através do modelo the life-career rainbow. Nesse modelo a carreira é compreendida como uma sequência de papéis sociais ocupados pelo indivíduo ao longo de sua vida: criança/filho, estudante, homem e mulher no lazer, cidadão, trabalhador, realizador de atividades domésticas (homemaker), cônjuge, pai e pensionista ou aposentado (Super, 1980). Desse modo, de acordo com a teoria que configura a aposentadoria como um processo de ajustamento da vida, no estágio de desengajamento, entende-se que um de seus desafios é a descentralização do papel de trabalhador e o desenvolvimento de outros papéis sociais que tragam sentido para a vida e a autorrealização (Shultz \& Wang, 2011).

A carreira ao longo da vida abarca diversas situações e experiências de trabalho e transições, como: (a) transição escola-trabalho (do ensino médio, técnico ou superior para o mundo do trabalho); (b) transições trabalho-trabalho [mudanças de emprego, de vínculos (de funções e cargos) e de atividades profissionais]; e (c) transição trabalho-aposentadoria (Heppner, 1998). Para Nardi (2014), a forma como o sujeito dá sentido às suas experiências refere-se a uma dinâmica intersubjetiva, onde ele se (re)inventa e (re)constrói sua identidade pessoal e profissional. Desta forma, no que se refere à transição trabalho-aposentadoria, considerando a representatividade do trabalho para a construção da subjetividade e identidade, como dizer adeus ao trabalho sem considerar os impactos nas questões identitárias? Quais estratégias podem ser utilizadas para auxiliar as pessoas nesse tipo de transição? Assim sendo, este relato de experiência possui o objetivo de descrever a implantação e os resultados de uma intervenção de preparação para a aposentadoria como uma estratégia para auxiliar o processo de transição nessa etapa do ciclo vital, a de desengajamento, cujas tarefas de desenvolvimento são relacionadas à desaceleração, ao planejamento da aposentadoria e à aposentaria propriamente dita, como apontam Lassance, Paradiso e Silva (2011).

A transição trabalho-aposentadoria implica em mudanças no cotidiano, as quais variam de acordo com as circunstâncias financeiras, psicossociais e de saúde, resultando em restruturações na identidade, nos relacionamentos e no sentido da vida (Anderson, Goodman, \& Schlössberg, 2012; Schlössberg, 2004; Wang \& Shultz, 2010). Para além da perspectiva da aposentadoria enquanto um processo de ajustamento, Shultz e Wang (2011) discorrem que ela acopla mais uma etapa (tardia) do desenvolvimento da carreira, que se refere a deixar um trabalho, ao desengajamento. Ou seja, pode-se optar entre duas possibilidades: se aposentar e parar e se aposentar e continuar trabalhando (bridge employment) na mesma ou em outra atividade profissional em tempo integral, parcial ou mediante trabalho voluntário (França \& Soares, 2009). E assim, galgar nova fase no desenvolvimento profissional. 
Ressalta-se que essa transição pode ser mais tranquila para algumas pessoas ou não. Para muitas, durante a transição trabalho-aposentadoria, são experimentados sentimentos ora ambivalentes, ora de perda, de ansiedade, medo e depressão (Duarte \& Melo-Silva, 2009; Shultz \& Wang, 2011; Zanelli, 2012). Portanto, seu sucesso depende de diversos fatores, sejam os financeiros, de saúde, psicossociais e de planejamento de atividades (Eismann, Verbeij, \& Henkens, 2019) e vem sendo objeto de investigação e intervenção há algumas décadas. São reconhecidas as contribuições de Schlössberg (2004), Shultz e Wang (2011), Hermida e Stefani (2012), Anderson et al. (2012), Wang e Wanberg (2017) e Eismann et al. (2019), entre outros, no contexto internacional. No Brasil, destacam-se os estudos de Duarte e Melo-Silva (2009), França e Soares (2009), Zanelli, Silva e Soares (2010), Soares e Costa (2011), Zanelli (2012), França, Menezes, Bendassolli e Macêdo (2013), Leandro-França, Murta e Iglesias (2014), Leandro-França, Murta e Villa (2014), Boehs, Medina, Bardagi, Luna e Silva (2017), Macêdo, Bendassolli e Torres (2017), Amorim e França (2019) e outros.

Há diversas linhas teóricas na Orientação Profissional e de Carreira (OPC) (desenvolvimentista, contextualista, life-span, transicional e life-design), as quais convergem no sentido de considerar que as diferentes características pessoais e contextuais interferem na habilidade de reavaliar a vida e a carreira e enfrentar o processo de mudança. Neste sentido, a teoria transicional proposta por Nancy Schlössberg (2004) justifica que as diversas transições requerem a avaliação de quatro fatores: a situação, o self, os apoios e as estratégias.

A análise da situação possibilita identificar o momento da vida em que as transições ocorrem, se são mudanças voluntárias ou involuntárias, o quanto de locus de controle interno se tem sobre a situação, as alterações em papéis valorizados e os estressores concomitantes, que tecem a avaliação subjetiva da situação (Schlössberg, 2004). A análise do self permite identificar a saliência e o balanço entre o papel de trabalhador e outros papéis sociais, interesses, resiliência, autoeficácia, a experiência com outras transições significativas e a abertura à mudança, além de aspectos sociodemográficos (Anderson et al., 2012; Schlössberg, 2004). Os apoios são as fontes e as possibilidades de ajuda disponíveis, destacando-se a empatia e o incentivo de pessoas importantes e próximas, o acesso às informações advindas de pessoas experientes em transições, de livros e de cursos que ensinem meios de buscar adaptabilidade nesta etapa da vida do desenvolvimento profissional. Por sua vez, estratégias referem-se à identificação de ações cognitivas que propiciem o ajustamento da nova condição de vida, baseando-se na avaliação dos pontos críticos dos outros três fatores para desenvolver um plano de ação concreto para lidar durante e após a transição (Anderson et al., 2012; Schlössberg, 2004). Na transição trabalho-aposentadoria, a estratégia refere-se à criação de projetos de futuro (França \& Soares, 2009; Soares \& Costa, 2011) e, ainda, no campo subjetivo, a elaboração do luto em relação ao que se deixa de conhecer, fazer, ser e conviver no trabalho e local da aposentadoria. 
Há duas vertentes antagônicas sobre a aposentadoria que são desenvolvidas subjetivamente pelo indivíduo a partir da situação em que se encontra diante deste evento esperado. A aposentadoria como um tempo de liberdade, de novas conquistas e de desenvolvimento pessoal tece a visão construtiva de encarar e gerenciar a mudança. No entanto, pode ser relacionada a uma fase de tensão e ansiedade sobre como lidar com a sensação de vazio existencial e solidão, de enfraquecimento do sentido da vida, de sentimentos de inutilidade e autodesvalorização, emergindo assim a visão restritiva (Zanelli et al., 2010; Zanelli, 2012). Ainda que seja uma mudança, na maior parte das vezes, voluntária e planejada, vivenciá-la não deixa de ser um processo imerso em expectativas e incertezas sobre o futuro, a identidade, o ajustamento dos padrões relacionais sociais e familiares e em como preencher o tempo livre agregando sentido à vida e, ao mesmo tempo deixar para trás a rotina de trabalho de longos anos de vida produtiva. Desse modo, verifica-se a necessidade de (re)pensar e (re)definir os projetos de futuro, de encontrar novas fontes de satisfação, autoestima, desenvolvimento pessoal e, para alguns, de subsistência, portanto, a preparação é fundamental (Schlössberg, 2004; Soares \& Costa, 2011; Zanelli et al., 2010). De acordo com a literatura nacional e internacional, quem se prepara para aposentar revela maior facilidade de adaptação, bem-estar e satisfação com a vida (Amorim \& França, 2019; Eismann et al., 2019; Seidl, Conceição, \& Nery, 2018; Wang \& Wanberg, 2017; Zanelli, 2012).

Além dos processos fundamentais desta transição, o cenário brasileiro de instabilidade econômica somado às mudanças sugeridas na reforma da previdência social vem promovendo mais inquietações quanto à decisão de solicitar a aposentadoria ou de continuar trabalhando (Freitas, Campos, \& Gil, 2017). Questões como o aumento da idade mínima e a estipulação de um teto salarial do benefício para todos destacam a necessidade de desenvolver estratégias de enfrentamento que estimulem o envelhecimento saudável, de modo que possam ter melhores condições de saúde, tanto para trabalhar por mais tempo, quanto para usufruir da aposentadoria tardia, além de englobar o planejamento da vida financeira para o futuro.

Outro panorama, a ser considerado neste relato, decorre do aumento da expectativa de vida no Brasil, que em 2017 era de 76 anos de idade (Instituto Brasileiro de Geografia e Estatística [IBGE], 2018). Observa-se, assim, o crescimento do índice de envelhecimento populacional. Em um cruzamento de dados históricos do IBGE foi constatada a expressiva mudança da população: no ano de 1920 o índice de envelhecimento populacional era de 10,6\%; em 2010 era de 39,3\% e; em 2040, a projeção é de 152,9\%, ou seja, quase 153 idosos para cada 100 jovens (Miranda et al., 2016). Com o estímulo de políticas públicas relativas à população idosa, já implementadas (Política Nacional do Idoso, Lei n 8.842 de 1994 e do Estatuto do Idoso, Lei $n^{\circ} 10.741$ de 2003), são recorrentes e requeridas ações em instituições públicas e privadas dirigidas à preparação, orientação e educação para a vida no estágio da aposentadoria. 
$\mathrm{Na}$ perspectiva da OPC, os denominados programas de preparação para a aposentadoria (PPAs), possuem como eixo norteador a compreensão subjetiva da transição na vida e na carreira, refletindo sobre a saliência do papel do trabalho e dos demais papéis sociais, a identidade socioprofissional, o rompimento do vínculo de trabalho e os impactos psicossociais (França \& Soares, 2009; Zanelli et al., 2010). Portanto, considerando os processos e as variáveis fundamentais que tangem este evento, pesquisadores e profissionais das áreas de OPC e de outras áreas do conhecimento são convidados a contribuir com investigações sobre intervenções que facilitem esse processo de mudança. Nesta perspectiva, este relato possui o objetivo de descrever e analisar o PPA implantado em um serviço público municipal e seus resultados. Com isso, visa contribuir com o campo científico de estudos interdisciplinares em aposentadoria.

\section{MÉTODO}

Trata-se de um relato de experiência profissional de uma intervenção em orientação para a aposentadoria de servidores públicos do município de Maringá, estado do Paraná. Nesta seção método são apresentados os participantes, a demanda, os objetivos e a implantação do programa.

\section{PARTICIPANTES}

Participaram do PPA durante quatro anos (2015, 2016, 2017 e 2018) 122 servidores públicos da cidade de Maringá, os quais estavam alocados em diversos cargos e áreas profissionais e possuíam níveis de escolaridade variados: ensino fundamental (18,84\%), ensino médio (44,25\%), ensino superior (18,84\%) e pós-graduação (18,03\%). Na época da intervenção possuíam em média 57 anos de idade ( $D P=1,52)$, sendo que $76,8 \%$ eram mulheres. Para fins deste estudo, foram analisadas as respostas à autoavaliação de 72 participantes.

\section{CUIDADOS ÉTICOS, PROCEDIMENTOS DE COLETA E ANÁLISE DE DADOS}

No primeiro encontro os participantes foram informados sobre a sistematização da experiência e os cuidados éticos garantindo-se ao sigilo quanto à identificação dos participantes, conforme Resolução do Conselho Nacional de Saúde (CNS) n. ${ }^{\circ}$ 510/2016. Assim, o Termo de Consentimento Livre e Esclarecido (TCLE) foi estabelecido. Como meio de investigar quais seriam as contribuições do PPA na perspectiva dos participantes, foram analisadas as respostas de um instrumento de autoavaliação realizado no último encontro, adaptado de Soares e Costa (2011), composto pelas frases para completar: (a) antes de iniciar os encontros eu me sentia...; (b) $\mathrm{O}$ que eu sentia quando participava dos encontros e realizava as atividades solicitadas...; (c) Os encontros me auxiliaram em... e (d) Agora estou me sentindo.... 
A seguir, as respostas foram inseridas no software de análise textual IRaMuTeQ (Interface de $\mathrm{R}$ pour les Analyses Multidimensionnelles de Textes et de Questionnaires), o qual viabiliza diferentes tipos de análise de dados textuais, desde as mais simples como a lexicografia básica e o cálculo de frequência de palavras, até análises multivariadas como classificação hierárquica descendente (CHD), análise de correspondências e análises de similitude (Camargo \& Justo, 2013). Considerando que as respostas dos participantes foram curtas (média de uma linha), optou-se pelo agrupamento e organização gráfica das palavras em função de sua frequência, ilustrada com a nuvem de palavras.

\section{DEMANDA, OBJETIVOS E IMPLANTAÇÃO}

A demanda inicial para desenvolver o PPA surgiu dos próprios trabalhadores, os quais participavam de treinamentos no centro de Capacitação de Pessoas da referida prefeitura e que solicitavam algum tipo de curso para quando fossem aposentar, em razão da rotina e dos longos anos dedicados ao serviço público. $O$ trabalho foi coordenado por uma doutora em Psicologia e a equipe de facilitadores era multidisciplinar, com profissionais da rede pública municipal (psicólogo, nutricionista, educador físico, médico, administrador de empresas, advogado) e professores de contabilidade e economia da universidade pública local. Como base para o delineamento do PPA foram utilizadas algumas fontes de conhecimento e intercâmbio de experiências, tais como o apoio técnico-científico do CarreiraLab da Universidade de São Paulo, campus de Ribeirão Preto; a participação no congresso da Associação Brasileira de Orientação Profissional (ABOP) e no minicurso E quando a minha aposentadoria chegar?, ministrado pelas criadoras do programa Aposenta-Ação (Soares \& Costa, 2011); visitação à universidade pública local para troca de experiências acerca do PPA por ela desenvolvido e; estudo de artigos e publicações científicas acerca de intervenções desta natureza.

Baseado na formação de grupos em OPC, o PPA objetivou proporcionar conteúdos informativos e práticas vivenciais reflexivas baseadas no autoconhecimento, no conhecimento do mundo sem o trabalho e dos projetos de futuro (Soares \& Costa, 2011). Compreendendo que a aposentadoria para alguns não significa parar de trabalhar, o PPA também englobou o conhecimento do mundo em outras atividades, por meio do redirecionamento na carreira. Dessa forma o programa possibilitou a articulação das dimensões da situação, do self, dos apoios e das estratégias para melhor ajustamento à nova condição de vida e carreira (Schlössberg, 2004). A divulgação de seu lançamento inicial, no ano de 2015 (e dos anos posteriores), ocorreu por meio de panfletos, comunicação eletrônica interna e no site da prefeitura, contendo objetivos, critérios para participação, datas e temas. Os encontros ocorreram em horário de trabalho (direito que é garantido em decreto municipal), a participação era voluntária e era possível inscrever quem pretendia aposentar em um período de dois anos. Após a realização das turmas pilotos foram revistos alguns pontos para ajuste de conteúdo, temas, técnicas, carga horária e facilitadores. Com isso, a estrutura final e que é a atual, foi instituída no ano de 2017, com oito encontros de quatro horas cada, realizados 
semanalmente. São atendidas de quinze a vinte pessoas por turma. Até o momento o PPA ainda não foi institucionalizado em portaria e/ou decreto municipal. A estrutura dos encontros e a avaliação do PPA, objeto deste estudo, são descritas na seção subsequente.

\section{RESULTADOS E DISCUSSÃO}

Os resultados da intervenção estão organizados em subseções: (a) os objetivos e as técnicas aplicadas por encontro e, (b) a análise da autoavaliação dos participantes no que se refere às contribuições do PPA.

\section{ESTRUTURA DOS ENCONTROS}

Os objetivos e técnicas de cada encontro estão resumidos na Tabela 1. Ao término dos encontros a coordenadora do PPA registrava suas impressões sobre as interações e o trabalho grupal em um diário de campo.

\section{Tabela 1.}

\section{Estrutura dos encontros do PPA}

\begin{tabular}{|c|c|c|}
\hline Encontros e objetivos & Conteúdo e técnicas & Facilitadores \\
\hline $\begin{array}{l}1^{\circ} \text { encontro: apresentar o } \\
\text { objetivo do PPA; realizar } \\
\text { a integração e a acolhida; } \\
\text { dialogar sobre as } \\
\text { representações sociais } \\
\text { do aposentado e } \\
\text { resgatar a trajetória de } \\
\text { vida e carreira. }\end{array}$ & $\begin{array}{l}\text { Atividade de apresentação. Contrato } \\
\text { psicológico grupal com a técnica } \\
\text { Novelo de lã (Soares, 2002). } \\
\text { Atividade O meu maior medo sobre } \\
\text { a aposentadoria é.... Debate acerca } \\
\text { das representações sociais da } \\
\text { aposentadoria. Técnica Linha da } \\
\text { Vida e Trajetória Profissional } \\
\text { (Soares, 2002). Atividade extraclasse } \\
\text { Escala de Mudança em } \\
\text { Comportamento de Planejamento } \\
\text { da Aposentadoria (EMCPA) de } \\
\text { Leandro-França, Murta e Iglesias } \\
\text { (2014). }\end{array}$ & $\begin{array}{c}\text { Uma } \\
\text { psicóloga. }\end{array}$ \\
\hline
\end{tabular}


Tabela 1. Continuação.

\begin{tabular}{|c|c|c|}
\hline Encontros e objetivos & Conteúdo e técnicas & Facilitadores \\
\hline $\begin{array}{l}2^{\circ} \text { encontro: informar os } \\
\text { trâmites legais da } \\
\text { aposentadoria; identificar } \\
\text { comportamentos } \\
\text { preditores da } \\
\text { aposentadoria (pela } \\
\text { EMCPA); apresentar } \\
\text { possibilidades de } \\
\text { desenvolver novas } \\
\text { atividades de trabalho } \\
\text { após a aposentadoria. }\end{array}$ & $\begin{array}{c}\text { Palestra sobre a } \\
\text { documentação para o } \\
\text { pedido de aposentadoria e } \\
\text { regras vigentes no } \\
\text { município sobre o tempo } \\
\text { de contribuição e a idade. } \\
\text { Após o intervalo os } \\
\text { resultados da escala foram } \\
\text { discutidos. Exposição } \\
\text { dialogada sobre o mercado } \\
\text { de trabalho para } \\
\text { aposentados e o } \\
\text { voluntariado. Atividade } \\
\text { extraclasse Roda da Vida } \\
\text { (Soares \& Costa, 2011). }\end{array}$ & $\begin{array}{l}\text { Dois advogados e } \\
\text { uma psicóloga. }\end{array}$ \\
\hline $\begin{array}{l}3^{\circ} \text { encontro: agregar } \\
\text { conhecimentos sobre } \\
\text { geração de renda e } \\
\text { empreendedorismo. }\end{array}$ & $\begin{array}{c}\text { Palestra sobre } \\
\text { empreendedorismo, nicho } \\
\text { de atuação, perfil para } \\
\text { empreender e formalização } \\
\text { da atividade. }\end{array}$ & $\begin{array}{c}\text { Um empresário } \\
\text { professor de } \\
\text { empreendedorismo. }\end{array}$ \\
\hline $\begin{array}{c}4^{\circ} \text { encontro: analisar a } \\
\text { saúde financeira para a } \\
\text { aposentadoria. }\end{array}$ & $\begin{array}{l}\text { A palestra de gestão } \\
\text { financeira pessoal versou } \\
\text { sobre o significado do } \\
\text { dinheiro, o gerenciamento } \\
\text { de receitas e despesas e } \\
\text { possibilidades de } \\
\text { investimentos. }\end{array}$ & $\begin{array}{l}\text { Um professor de } \\
\text { Contabilidade e um } \\
\text { professor de } \\
\text { Economia. }\end{array}$ \\
\hline $\begin{array}{l}5^{\circ} \text { encontro: avaliar a } \\
\text { satisfação com a vida e } \\
\text { debater as possíveis } \\
\text { mudanças na dinâmica } \\
\text { familiar/conjugal. }\end{array}$ & $\begin{array}{l}\text { Discussão da Roda da Vida. } \\
\text { Técnica Gosto e Faço } \\
\text { (Soares, 2002). Exposição } \\
\text { dialogada sobre mudanças } \\
\text { na dinâmica familiar/ } \\
\text { conjugal. Atividade } \\
\text { extraclasse: Plano de ação } \\
\text { com a Família (autoria da } \\
\text { coordenadora do PPA). }\end{array}$ & Uma psicóloga. \\
\hline
\end{tabular}


Tabela 1. Continuação.

\begin{tabular}{|c|c|c|}
\hline Encontros e objetivos & Conteúdo e técnicas & Facilitadores \\
\hline $\begin{array}{c}6^{\circ} \text { encontro: } \\
\text { conscientizar acerca do } \\
\text { envelhecimento saudável } \\
\text { com ênfase na } \\
\text { alimentação equilibrada } \\
\text { e na prática de atividades } \\
\text { físicas. }\end{array}$ & $\begin{array}{l}\text { Primeira palestra desmistificou } \\
\text { alimentos industrializados e } \\
\text { orientou para alternativas } \\
\text { alimentares mais saudáveis. } \\
\text { Segunda palestra abordou os } \\
\text { benefícios do exercício físico } \\
\text { regular e informou sobre espaços } \\
\text { públicos esportivos no município. }\end{array}$ & $\begin{array}{c}\text { Uma } \\
\text { nutricionista e } \\
\text { uma } \\
\text { educadora } \\
\text { física. }\end{array}$ \\
\hline $\begin{array}{c}7^{\circ} \text { encontro: } \\
\text { conscientizar acerca do } \\
\text { envelhecimento saudável } \\
\text { com ênfase no } \\
\text { autocuidado da saúde e } \\
\text { dialogar sobre os } \\
\text { projetos familiares } \\
\text { construídos para a } \\
\text { aposentadoria. }\end{array}$ & $\begin{array}{l}\text { A primeira palestra abordou } \\
\text { algumas doenças comuns no } \\
\text { estágio da velhice, como detectar } \\
\text { sinais e prevenir com hábitos e } \\
\text { estilo de vida saudáveis e } \\
\text { esclareceu dúvidas sobre a vida } \\
\text { sexual nesta etapa da vida. Foi } \\
\text { retomada a atividade feita com a } \\
\text { família e orientação para a } \\
\text { atividade extraclasse Plano de } \\
\text { ação para uma aposentadoria } \\
\text { bem-sucedida (Leandro-França, } \\
\text { Murta, \& Villa, 2014). }\end{array}$ & $\begin{array}{c}\text { Uma médica e } \\
\text { uma } \\
\text { psicóloga. }\end{array}$ \\
\hline $\begin{array}{l}8^{\circ} \text { encontro: planejar os } \\
\text { projetos de futuro e } \\
\text { refletir sobre as ações } \\
\text { necessárias para atingi- } \\
\text { los. Encerrar o PPA e } \\
\text { obter feedback dos } \\
\text { participantes. }\end{array}$ & $\begin{array}{l}\text { Exibição do documentário } \\
\text { Envelhescência de Gabriel } \\
\text { Martinez, seguido de discussão do } \\
\text { Plano de ação. Retomada da } \\
\text { atividade O meu maior medo é... } \\
\text { do } 1^{\circ} \text { dia. Cada membro leu a } \\
\text { resposta aconselhando o autor } \\
\text { anônimo em como lidar com esse } \\
\text { medo. Autoavaliação adaptada de } \\
\text { Soares e Costa (2011). }\end{array}$ & $\begin{array}{c}\text { Uma } \\
\text { psicóloga. }\end{array}$ \\
\hline
\end{tabular}

\section{AVALIAÇÃO DO PPA}

Entre 2015 e 2018 participaram do PPA 122 pessoas, no entanto, a referida autoavaliação passou a ser aplicada a partir das turmas de 2017 e 2018, após formatação final do programa, totalizando 72 respondentes. Os resultados gerados pelo IRaMuTeQ compuseram nuvens de palavras (com frequência $>5$ ). A Figura 1 aponta os sentimentos e palavras recorrentes reportadas pelos participantes antes da intervenção. 


\section{preocupado \\ apreensivo agora \\ 产 đaposentar \\ 产 dia $\frac{0}{2}$ vidajá dúvida \\ ¿ estar muito \\ aposentadoria \\ inseguro mais \\ bemnãocurioso \\ medo}

Figura 1.

Nuvem de Palavras de Sentimentos pré-intervenção.

Assim, antes da intervenção os participantes se expressaram por meio das seguintes palavras: inseguro, dúvida, saber, bem, curioso, medo e preocupado, entre outras. $O$ desengajamento do ato de trabalhar se relaciona às mudanças em todas as esferas da vida, aos sentimentos de insegurança, à apreensão e medo, que são comuns e decorrentes da vivência antecipada do luto quanto à perda do papel identitário do trabalho, como apontam Duarte e Melo-Silva (2009) e Shultz e Wang (2011). Além disso, há incertezas sobre como ocupariam o tempo livre. Para Zanelli (2012) estes sentimentos negativos, embora esperados, podem derivar de um foco excessivo nas perdas e privações como as relacionadas às atividades de trabalho, ao status, aos relacionamentos, ao reconhecimento profissional entre outros. Nesta configuração, o tempo livre deixa de ser percebido como oportunidade para novas descobertas, reduzindo a capacidade de enfrentamento dos estressores da aposentadoria. Os participantes também destacaram o desconhecimento das regras vigentes de aposentadoria, incluindo a capacidade financeira. Este cenário remonta ao que Soares e Costa (2011) afirmam, de que muitas pessoas esperam tanto tempo pela aposentadoria que, quando ela ocorre, possuem dúvidas e sentem-se perdidas ou não conseguem colocar em ação as metas vagamente idealizadas para o futuro próximo quando não há planejamento (Eismann et al., 2019). Alguns participantes também descreveram se sentirem bem, revelando que a aposentadoria pode ser avaliada subjetivamente de forma construtiva (sentir-se bem) e/ou restritiva (insegurança, dúvidas e apreensão), dependendo das variáveis pessoais e ambientais (Zanelli et al., 2010). Registraram, também, a curiosidade sobre o conteúdo do programa. Os sentimentos presentes no processo de intervenção são expressos por meio das palavras apresentadas na Figura 2. 


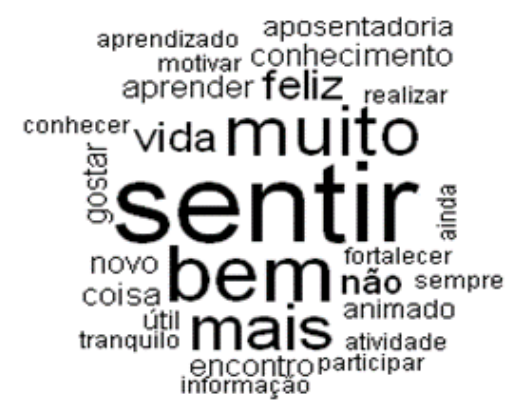

Figura 2.

Nuvem de Palavras de Sentimentos durante a intervenção.

A percepção de mudanças dos recursos internos no decorrer da intervenção foi observada por meio das palavras: muito, bem, mais, feliz, vida, não, aprendizado e realizar, entre outras. As atividades desenvolvidas objetivaram estimular pensamentos no sentido de ressignificar a avaliação subjetiva da situação da transição, a partir de reflexões acerca de si mesmo (redescoberta do self, de como ocupar o tempo, de ampliar os papéis sociais, dos apoios disponíveis e de elaborar estratégias para adaptação/projetos de futuro) e do conhecimento do mundo sem o trabalho e/ou do mundo a partir de novas configurações profissionais. Dessa forma, as atividades abarcaram todas as dimensões relevantes do gerenciamento das transições na carreira (Schlössberg, 2004). A percepção de estarem em aprendizagem durante o programa e de terem obtido conhecimentos reiteram o seu papel psicoeducativo propiciado pela diversidade de temas abordados, conforme sugerem França e Soares (2009) e Soares e Costa (2011). A Figura 3 apresenta a nuvem das palavras que simbolizam os encontros.

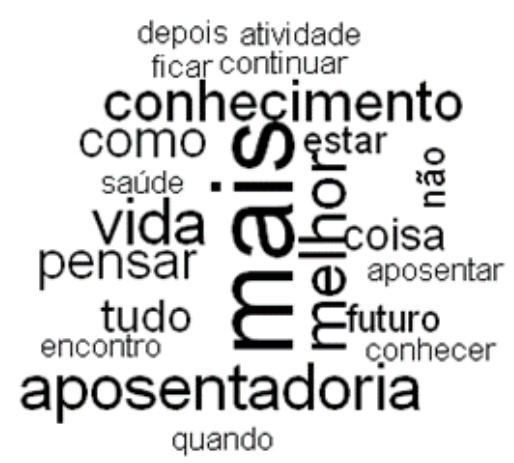

Figura 3.

Nuvem de Palavras de Os encontros auxiliaram. 
As palavras frequentes sobre o que os encontros auxiliaram foram: mais, melhor, aposentadoria, pensar, vida, como, conhecimento e futuro, entre outras. Ajudaram, portanto, na descoberta de como e o que fazer, a planejar a vida e o futuro e a decidir se solicitariam a aposentadoria. De acordo com Macêdo et al. (2017) a intenção de aposentar e o respectivo ajustamento da vida se relacionam a uma imagem positiva deste evento, de usufruí-lo com atividades que tragam bem-estar e de investir nos relacionamentos familiares, aspectos que foram amplamente debatidos durante os encontros. Ademais, verificou-se que diversos participantes relataram interesse sobre empreender e atuar no mercado de trabalho em outra profissão, corroborando com a perspectiva deste momento ser mais uma etapa do desenvolvimento da carreira, possibilitando o seu redirecionamento (França \& Soares, 2009; Shultz \& Wang, 2011). A Figura 4 mostra as palavras que expressam os sentimentos após a intervenção.

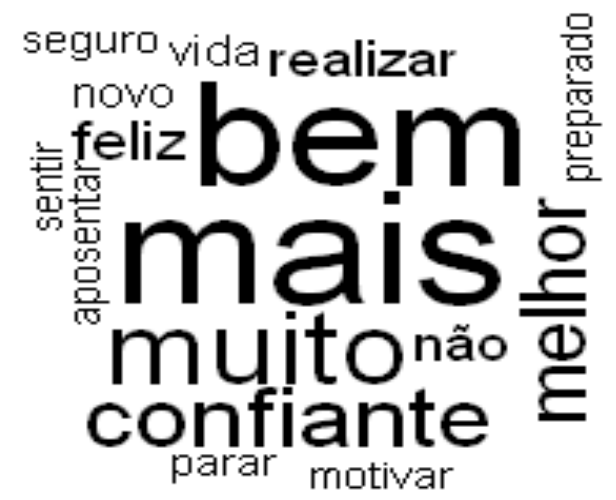

Figura 4.

Nuvem de Palavras de Sentimentos pós-intervenção.

As palavras da Figura 4 revelam que após a intervenção as pessoas se sentiram mais confiantes, seguras e felizes, assim como preparadas e motivadas para o novo e para futuras realizações. Estes resultados evidenciam a contribuição do programa, corroborando Zanelli et al. (2010) e Soares e Costa (2011), no que se refere aos subsídios internos e externos (via projetos de futuro objetivos com metas) que os PPAs proporcionam para o enfrentamento dos estressores inerentes à aposentadoria. Os projetos mais frequentes foram viajar, praticar esportes, aprender um instrumento musical, artesanatos ou idiomas, conhecer novas pessoas, passar mais tempo com a família, curtir a vida a dois, cursar nova faculdade, abrir um negócio ou prestar serviços, entre outros.

A partir das nuvens de palavras, constatou-se que o PPA possibilitou reflexões acerca da avaliação subjetiva da aposentadoria (dimensão situação). Os encontros auxiliaram na redescoberta do self, na identificação e resgate dos interesses e habilidades as quais podem ser investidas em outros papéis sociais e no autocuidado em relação à saúde (dimensão selff). Destacaram a importância de buscar e ativar fontes de ajuda nos relacionamentos sociais, familiares e meios de gerar renda e cuidar da saúde financeira (dimensão apoios). Por fim, direcionaram 
a elaboração dos projetos de futuro num plano real, concreto e objetivo (dimensão estratégias), de modo que os participantes pudessem elencar e equilibrar todas as dimensões do gerenciamento transicional e, desse modo, fosse facilitado o ajustamento à aposentadoria, visando à continuidade da vida com sentido e realizações pessoais e/ou profissionais.

\section{CONSIDERAÇÕES FINAIS}

Considera-se que o objetivo de descrever a estrutura da intervenção em preparação para a aposentadoria e de apresentar seus resultados foi atingido. No entanto, há pontos a serem aprimorados para novas edições do programa.

Algumas etapas consideradas relevantes em orientações para a aposentadoria não foram contempladas neste programa, como as entrevistas de diagnóstico inicial, o acompanhamento (follow-up) e a aferição sistemática da eficácia do programa. Para Soares e Costa (2011) a entrevista inicial ajuda a trazer para o grupo pessoas potencialmente interessadas e comprometidas em participar, respalda os instrutores a respeito de expectativas daqueles que participarão e auxilia na condução do grupo, mas mais do que isso, um diagnóstico inicial permite também mensurar as condições de chegada dos participantes. Ações de follow-up após término do programa são recomendadas (França \& Soares, 2009; Leandro-França, Murta, \& Villa, 2014) para ofertar nova orientação àqueles que apresentem dificuldades de ajustamento e a obter mais pistas de variáveis que interferem na dificuldade de adaptação à situação de transição.

E, quanto às medidas padronizadas de avaliação, Pazzim e Marin (2016) alertam que as intervenções em âmbito nacional as utilizam pouco, provavelmente pelas escassas opções de escalas desenvolvidas neste campo. Boehs et al. (2017) identificaram apenas quatro escalas no Brasil. A etapa da avaliação ajuda a assegurar o uso adequado dos recursos e a implementar intervenções que realmente tragam benefícios aos participantes (Leandro-França, Murta, \& Iglesias; 2014). O instrumento qualitativo aplicado neste relato foi útil para levantar as contribuições do PPA, no entanto, por ser auto avaliativo com questões abertas, é passível de vieses. Dessa forma, medidas quantitativas pré e pós intervenção, associadas às técnicas qualitativas, aperfeiçoarão a verificação da eficácia.

Considerando as particularidades econômicas, populacionais e previdenciárias que o país vem enfrentando, desafios são lançados à OPC e à sociedade em geral. Se as pessoas terão que trabalhar por mais tempo e terão um limite salarial do benefício social, ter boas condições de saúde física e financeira e o acesso do idoso ao trabalho digno são essenciais para a qualidade de vida, a aposentadoria e o envelhecimento. Ressalta-se a importância de políticas públicas que abranjam esse cenário. Em termos práticos sugere-se a inserção de temas de educação financeira e em saúde nas grades curriculares em diferentes níveis da educação. Outra preocupação versa sobre o ageismo no mercado de trabalho, que dificulta a complementação de renda e/ou da continuidade de trabalho até obter o benefício 
previdenciário social. Portanto, políticas governamentais de incentivo ao trabalho para idosos, a desburocratização para o microempreendedor operar e a regulamentação na legislação para o bridge employment, precisam ser estudadas e alinhadas à realidade brasileira. E, por último, como a maioria destas intervenções ocorre em instituições públicas (Boehs et al.; 2017), como preparar os trabalhadores de empresas privadas, os profissionais liberais, os terceirizados es que vivem na informalidade? Neste sentido, os PPAs precisam ter amplo acesso a todos os trabalhadores, incentivados pelo governo, ofertados por programas sociais comunitários.

Compreendendo que este trabalho não esgota as possibilidades das discussões e ações no preparo para a vida na aposentadoria e, em busca de mais evidências, sugere-se que outras experiências profissionais sejam compartilhadas considerando os desafios para o exercício futuro da OPC e das ciências interdisciplinares envoltas à temática.

\section{REFERÊNCIAS}

Amorim, S. M., \& França, L. H. F. P. (2019). Retirement well-being: A systematic review of the literature. Temas em Psicologia, 27(21), 155-172. doi:10.9788/TP2019.1-12

Anderson, M. L., Goodman, J., \& Schlössberg, N. K. (2012). Counseling adults in transitions: Linking Schlössberg's theory with practice in a diverse world. (4th ed.). New York, NY: Springer Publishing Company.

Boehs, S. T. M., Medina, P. F., Bardagi, M. P., Luna, I. N., \& Silva, N. (2017). Revisão da literatura latinoamericana sobre aposentadoria e trabalho: Perspectivas psicológicas. Revista Psicologia: Organizações e Trabalho, 17(1), 54-61. doi:10.17652/rpot/2017.1.11598

Camargo, B. V., \& Justo, A. M. (2013). IRAMUTEQ: Um software gratuito para análise de dados textuais. Temas em Psicologia, 21(2), 513-518. doi:10.9788/TP2013.2-16

Duarte, C. V., \& Melo-Silva, L. L. (2009). Expectativas diante da aposentadoria: Um estudo de acompanhamento em momento de transição. Revista Brasileira de Orientação Profissional, 10(1), 45-54.

Eismann, M., Verbeij, T., \& Henkens, K. (2019). Older workers' plans for activities in retirement: The role of opportunities, spousal support, and time perception. Psychology and Aging, 34(5), 738-749. doi:10.1037/pag0000377

França, L. H. F. P., Menezes, G. S., Bendassolli, P. F., \& Macêdo, L. S. S. (2013). Aposentar-se ou continuar trabalhando? O que influencia esta decisão? Psicologia Ciência e Profissão, 33(3), 548-563. doi:10.1590/s1414-98932013000300004

Freitas, M. C. de; Campos, T. D., \& Gil, C. A. (2017). Expectativas e concepções de trabalho na velhice em homens na meia-idade. Estudos Interdisciplinares em Psicologia, 8(2), 43-64. doi: 10.5433/2236-6407.2016v8n2p43

Heppner, M. J. (1998). The career transitions inventory: Measuring internal resources in adulthood. Journal of Career Assessment, 6(2), 135-145. doi:10.1177/106907279800600202

Hermida, P., \& Stefani, D. (2012). La jubilación como un factor de estrés psicosocial: Un análisis de los trabajos científicos de las últimas décadas. Perspectivas en Psicología, 8(2), 101-107.

Instituto Brasileiro de Geografia e Estatística [IBGE] (2018). Síntese de indicadores sociais: Uma análise das condições de vida da população brasileira. Rio de Janeiro, RJ: IBGE.

Lassance, M. C. P., Paradiso, A. C., \& Silva, C. B. (2011). Terceira demanda-chave para a orientação profissional: Como ajudar o indivíduo a desenvolver sua carreira? Enfoque Desenvolvimentista e Evolutivo. In M. A. Ribeiro \& L. L. Melo-Silva (Eds.), Compêndio de orientação profissional e de carreira: Perspectivas históricas e enfoques teóricos clássicos e modernos (Vol. 1). São Paulo, SP: Vetor.

Leandro-França, C., Murta, S. G., \& Iglesias, F. (2014). Planejamento da aposentadoria: Uma escala de mudança de comportamento. Revista Brasileira de Orientação Profissional, 15(1), 75-84. 
Leandro-França, C., Murta, S. G., \& Villa, M. B. (2014). Efeitos de uma intervenção breve no planejamento para a aposentadoria. Revista Psicologia: Organizações e Trabalho, 14(3), 257270.

Macêdo, L. S. S., Bendassolli, P. F., \& Torres, T. de L. (2017). Representações sociais da aposentadoria e intenção de continuar trabalhando. Psicologia e Sociedade, 29(1), 1-11. doi:10.1590/18070310/2017v29145010

Miranda, G. M. D.; Mendes, A. C. G., \& Silva, A. L. A. (2016). O envelhecimento populacional brasileiro: Desafios e consequências sociais atuais e futuras. Revista Brasileira de Geriatria e Gerontologia, 19(3), 507-519.

Nardi, H. C. (2014). Ética, trabalho e subjetividade. Porto Alegre, RS: Editora da UFRGS.

Pazzim, T. A., \& Marin, A. (2016). Programas de preparação para aposentadoria: Revisão sistemática da literatura nacional. Revista Brasileira de Orientação Profissional, 17(1), 91-101.

Schlössberg, N. K. (2004). Retire smart, retie happy: Finding your true path in life. Washington, DC: American Psychological Association.

Seidl, J., Conceição, M. I. G.; \& Nery, M. P. (2018). Aposentadoria e a dificuldade de dizer adeus ao papel profissional. Revista Brasileira de Psicodrama, 26(1), 133-139. doi:10.15329/23180498.20180006

Soares, D. H. P. (2002). A escolha profissional: Do jovem ao adulto. São Paulo, SP: Summus.

Soares, D. H. P. \& Costa, A. B. (2011). Aposenta-ação: Aposentadoria para ação. São Paulo, SP: Vetor.

Shultz, K. S., \& Wang, M. (2011). Psychological perspectives on the changing nature of retirement. American Psychologist, 66(3), 170-179. doi:10.1037/a0022411

Super, D. E. (1980). A life-span, life-space approach to career development. Journal of Vocational Behavior, 16(3), 282-298.

Wang, M., \& Shultz, K. S. (2010). Employee Retirement: A review and recommendations for future investigation. Journal of Management, 36(1), 172-206. doi:10.1177/0149206309347957

Wang, M., \& Wanberg, C. R. (2017). 100 years of applied psychology research on individual careers: From career management to retirement. Journal of Applied Psychology, 102(3), 546-563. doi: 10.1037/apl0000143

Zanelli, J. C. (2012). Processos psicossociais, bem-estar e estresse na aposentadoria. Revista Psicologia: Organizações e Trabalho, 12(3), 329-340.

Zanelli, J. C., Silva, N., \& Soares, D. H. P. (2010). Orientação para aposentadoria nas organizações de trabalho: Construção de projetos para o pós-carreira. Porto Alegre, RS: Artmed.

\section{CONFLITOS DE INTERESSES}

Não há conflitos de interesse.

\section{SOBRE OS AUTORES}

Marlize Paulo da Silva é psicóloga pela Universidade Estadual de Maringá, mestre em Administração de Organizações e doutora em Psicologia pela Universidade de São Paulo, Ribeirão Preto. É psicóloga da Prefeitura Municipal de Maringá. Trabalha na linha de pesquisa: "Orientação profissional, educação e desenvolvimento de carreira" e "Psicologia do Trabalho".

E-mail: marlizepaulo@hotmail.com

(1) https://orcid.org/0000-0003-1049-7375

Lucy Leal Melo-Silva é psicóloga, livre-docente e professora sênior do Departamento de Psicologia da Faculdade de Filosofia, Ciências e Letras de Ribeirão Preto da Universidade de São Paulo (FFCLRPUSP). Coeditora da Revista Brasileira de Orientação Profissional. Linhas de pesquisa: "Orientação profissional, educação e desenvolvimento de carreira" e "Desenvolvimento socioemocional e de carreira". Pesquisadora CNPq.

E-mail: lucileal@ffclrp.usp.br

(1) http://orcid.org/0000-0002-5890-9896 